\title{
O JOGO DE BOLA: UMA ANÁLISE SOCIOESPACIAL DOS TERRITÓRIOS DOS PELADEIROS
}

\author{
Alexsander Batista e Silva* \\ Eguimar Felício Chaveiro**
}

\section{RESUMO}

O objetivo deste trabalho foi o de analisar as territorialidades dos peladeiros no setor Mansões Paraíso, em Aparecida de Goiânia-Goiás. Para realizá-lo foram utilizados alguns procedimentos metodológicos, os quais constam de duas etapas: o trabalho de "gabinete" e o trabalho de campo. A pelada furta a institucionalidade do futebol profissional, posto que para o peladeiro as regras, os locais e os horários figuram num segundo plano. Para o peladeiro, importante mesmo é o momento de sociabilidade proporcionado pela pelada. No jogo rápido de nosso trabalho, a tentativa foi dar o pontapé inicial para uma reflexão geográfica sobre os territórios informais do futebol.

PALAVRAS-CHAVE: jogador profissional - peladeiro - futebol - territórios - sociabilidade.

\section{INTRODUÇÃO}

\begin{abstract}
A ssim como a maioria dos meninos brasileiros sonha ser um jogaAdor de futebol, eu também quis ser um artista do mundo da bola. Naqueles tempos, de moleque no interior, jogava pelada de domingo a domingo. Como torcedor fui bastante assíduo, sempre assistindo aos jogos de futebol que ocorriam na minha cidade. Acompanhava também todos os jogos transmitidos pela TV - Copas do Mundo, Libertadores da América, Brasileirão e Campeonatos Estaduais.
\end{abstract}

\footnotetext{
* Mestrando pelo Programa de Pesquisa e Pós-Graduação em Geografia do Instituto de Estudos Sócio-Ambientais da UFG e professor da Rede Estadual de Educação.

** Doutor em Geografia e professor do Instituto de Estudos Sócio-Ambientais.
} 
A minha realidade, vinculada ao plano mais íntimo do meu desejo e da minha relação com a cultura da nação, pode - e deve - ser universalizada. Igual a mim, outros tantos da minha geração, anterior e posterior a ela, tinham o mesmo sonho. Isso quer dizer que o futebol pertence à alma individual e coletiva da nação. As suas tramas, os jogos, o processo de socialização que provoca, o seu papel de instituir pertencimentos, a sua ação social de criar imagens, afirmam esse papel.

O tema "futebol" surge então por ser algo que gosto e também por abrir a possibilidade de realização de um trabalho num campo novo e pouco explorado pela ciência geográfica. Além disso, o futebol, esporte mais praticado do planeta, apresenta-se ao brasileiro como elemento fundante da identidade nacional. Portanto, possui uma gigantesca importância neste contexto. Na atualidade, o futebol em escala mundial aparece inserido no rol do esporte-espetáculo. Isso traz repercussões nos aspectos culturais e sociais, propiciando alterações nas formas de organização espaço-territoriais.

A pelada é aqui compreendida como fenômeno social que recorta as paisagens, principalmente dos lugares periféricos. Os atores responsáveis por territorializá-la no espaço são os peladeiros. Estes, na construção das peladas, criam e recriam territórios, alteram paisagens, instituem novos ritmos ao mundo vivido das pessoas, enfim, dinamizam o espaço geográfico. A partir de tais premissas, buscaremos analisar as territorialidades dos peladeiros no setor Mansões Paraíso em Aparecida de Goiânia, Goiás, com o intuito de compreender os elementos constitutivos e estruturantes das peladas, assim como o universo vivido do peladeiro e suas relações com o espaço geográfico.

\section{AS TERRITORIALIDADES DO FUTEBOL}

No Brasil, o futebol é, efetivamente, como afirma Silva e Votre (2005), um dos grandes eventos, aglutinador de emoções e partícipe da construção do espírito nacional. No mesmo sentido, para Machado (2005), o futebol se faz presente em inúmeras cenas do cotidiano do brasileiro. Em virtude disso, torna-se evidente a pujança que o futebol conquista ao longo de sua história no território do Brasil.

O esporte planetário criou suas raízes no Brasil e transformou-se em um dos principais cartões de visita do país (FÁVERO, 2004). O

2 SILVA, A. B.; CHAVEIRO, E. F. O jogo de bola: uma análise socioespacial ... 
vigor do futebol como processo social é uma construção histórica. De acordo com Mascarenhas (1998, p. 93-94),

a montagem deste amplo cenário é fruto dos processos articulados de formação de uma nação (e toda a sua carga simbólica) e de estruturação de um território em acelerada urbanização. Inicialmente funcionando como apenas mais um modismo importado dos ingleses, prática restrita aos poucos jovens da elite republicana, o futebol se popularizou rapidamente. Sua difusão espacial expressiva permitiu que se tornasse uma poderosa instituição nacional.

Os clubes de futebol dinamizam a vida, principalmente, das grandes cidades. Aqueles imprimem um movimento que supera a antiga monotonia das paisagens diárias. A cidade se movimenta em função dos treinos, dos amistosos, dos jogos de campeonato, de um jogador descoberto, da derrota do outro. "A metrópole, o grande mundo de milhões de indivíduos, se divide pelos vários clubes, e, aos sábados e domingos, às vezes mais, retempera-se na torcida do quadro favorito" (CASTRO, 1962, p. 117).

$\mathrm{O}$ futebol no Brasil não interessa apenas às grandes aglomerações humanas, mas, igualmente, aos pequenos núcleos que vão desde as fazendas até as pequenas cidades, sedes de município, lugarejos e outros. Conforme Castro (1962, p. 114), "a capela e o campo de futebol são os seus elementos substanciais. O campo de futebol inverteu a história das povoações. Antes, os lugarejos nasciam em redor da capela". No mesmo sentido, Alencar (1970, p. 79) afirma ainda que, "a paisagem das pequenas cidades e vilas sertanejas já não se limitava ao prédio velho da cadeia e a pracinha com a igreja fazendo de zagueiro líbero. Agora o gramado com balisas passaria a integrá-la em definitivo".

Por conseguinte, a força com que o futebol se projeta no âmbito do vivido do brasileiro se dá também no nível do futebol amador ou não profissional. Vide a enorme quantidade de campos, ou melhor, de espaços destinados à prática de futebol e o grande contingente de indivíduos que jogam bola somente por prazer. Os campos espalham-se tanto pelas cidades como pela zona rural, pela periferia e pelo centro da cidade, em locais voltados especificamente à sua prática ou improvisados. O futebol pode e é praticado em quase todos os lugares, no colégio, na fábrica, no exército, na penitenciária, na rua entre outros. 
Na prática informal/amadora do esporte acontece com freqüência o processo de refuncionalização dos espaços, termo utilizado por Santos (1997). Os peladeiros na construção de sua territorialidade imprimem uma transformação nos espaços, edificando, assim, os territórios das peladas. Territórios estes, que às vezes são possuidores de um horizonte espacial e temporal efêmero como, por exemplo, um jardim, uma calçada, um lote baldio, uma rua. Esta tem como função principal servir ao tráfego de veículos e pessoas. Todavia, principalmente, nas tardes dos finais de semana e feriados são apropriadas pelos amantes da bola, passando a figurar como espaços para a prática das peladas. A rua temporariamente ganha nova função passando a se constituir num território das peladas.

\section{A PELADA - UMA INSTÂNCIA DOS TERRITÓRIOS DO FUTEBOL AMADOR}

Na contemporaneidade podem-se vislumbrar, grosso modo, duas grandes territorialidades do futebol. A do futebol profissional, ou seja, aquela do futebol-espetáculo, dos grandes jogos transmitidos pela TV, dos estádios lotados, dos craques do mundo da bola. E a amadora, praticada a qualquer hora e lugar pelos amantes do futebol, os quais jogam pelo simples prazer proporcionado pelo lúdico do futebol - os peladeiros.

Ao que parece, existe pelo menos dois grupos dentro do futebol considerado como não profissional/amador. Um, que estaria no pólo extremo do amadorismo, que na construção do território da pelada tudo pode ser, quase sempre é, improvisado. Outro se localizaria num meio termo entre o profissional e o amador, o qual pode-se denominar de amador-profissional. Este se refere aos campeonatos de futebol amador. Apesar de não serem profissionais, tais peladas contam com certa institucionalidade - juiz, jogos de camisa, torcida, espaços específicos entre outras.

As peladas constituem-se num fenômeno sociocultural muito presente na periferia dos centros urbanos. Os atores das peladas, ou seja, os peladeiros apropriam-se, mesmo que temporariamente, de determinado espaço para prática do futebol (não-profissional), construindo assim os territórios das peladas. Os peladeiros territorializam-se temporariamente num determinado espaço, imprimindo as marcas de sua cultura 
futebolística. Entende-se como cultura futebolística do peladeiro toda uma gama de práticas materiais ou simbólicas que permite a ele que se conheça e seja conhecido como diferente do outro.

$\mathrm{O}$ agir dos peladeiros no espaço, para construir o território das peladas expressa sua territorialidade. Territorialidade essa que se faz mediante projeção da cultura futebolística num determinado espaço, de maneira a conferir-lhe a condição de território. Os territórios das peladas apresentam-se à margem da visibilidade global, ou melhor, são territórios pouco visíveis. Ao se falar de futebol, em geral são lembradas - inclusive pelas poucas produções acadêmicas -, somente as grandes partidas do futebol-espetáculo.

Torna-se necessário, neste momento, elucidar o conceito de pelada, isso por figurar como elemento central neste trabalho. A palavra pelada vem de péla que significa bola, a qual era usada em jogos e brincadeiras; e péla por sua vez tem sua origem no latim vulgar da palavra pilella. Atualmente, o termo pelada é utilizado para designar uma vertente mais "periférica" do futebol, ou seja, um futebol jogado entre amadores e, geralmente, em campos improvisados. E o peladeiro sendo, então, esse jogador amador que participa da pelada (HOUAISS; VILLAR, 2001).

Pensando além da origem etimológica e do significado que o dicionário traz, talvez exista uma relação entre a pelada no sentido do jogo e a nudez. Isso por que o jogo informal do futebol apresenta o caráter do improviso e, com relação ao uniforme, quando se necessita de uma diferenciação entre os times, costumeiramente uma das equipes joga sem camisa. Não esquecendo também que geralmente os peladeiros atuam com os pés descalços e no campo desnudo (sem grama). Enfim, pode ser que o caráter da nudez tenha influenciado o nome atribuído a essa instância do futebol.

A pelada constitui-se como a instância mais amadora do futebol, e por isso apresenta no ethos constitutivo o improviso. A pelada furta as regras do futebol profissional, acontece em qualquer lugar e a qualquer hora do dia ou da noite e suas regras das peladas são flexíveis. As peladas ainda podem apresentar várias modalidades - golzinho, golzão, gol dentro da área, soldadinho, primeirinha, cada um por si e outros. A escolha dessa ou daquela modalidade está ligada a dois elementos. Primeiro, o gosto do peladeiro por uma ou outra; segundo, o espaço para a prática e o número de peladeiros. 


\section{OS TERRITÓRIOS DAS PELADAS NO SETOR MANSÕES PARAÍSO EM APARECIDA DE GOIÂNIA}

O município de Aparecida de Goiânia localiza-se na região metropolitana da capital do Estado de Goiás. Região essa, composta por onze municípios que possuem 1.639.516 habitantes, totalizando quase $33 \%$ da população de todo o Estado de Goiás. Aparecida de Goiânia é possuidor de uma extensão territorial de $288,456 \mathrm{~km}^{2}$ e uma população de 336.392 habitantes, segunda maior do Estado (SEPLAN, 2003).

$\mathrm{O}$ universo futebolístico do município apresenta-se vasto e bastante diversificado. Os moradores de Aparecida de Goiânia são grandes amantes do futebol, vide os inúmeros espaços refuncionalizados para a sua prática - ruas, lotes baldios, praças, calçadas e outros - ou mesmo os espaços destinados especificamente para o futebol, sejam esses públicos - quadras, ginásios, terrões ${ }^{1}$-, ou privados - chácaras com campos para aluguel, quadras particulares, pequenos gramados nas mansões da elite e outros. E, nos territórios das peladas, oficiais ou amadoras, os peladeiros são os mais diversos - crianças, jovens, adultos, negros, brancos, ricos, pobres, mulheres. ${ }^{2}$

Durante um mês e meio da pesquisa, na segunda quinzena do mês de outubro e mês de novembro de 2005, foram realizadas observações e entrevistas, identificando-se dezesseis territórios das peladas. Dentre eles, doze são espaços refuncionalizados temporariamente em função da pelada - as peladas realizadas na rua e em lotes baldios -, os outros quatro são espaços com destinação específica para a prática do futebol, sendo dois públicos - terrões - e dois privados - uma quadra de esportes e uma chácara com campos para aluguel.

Ao se observar a distribuição espacial da prática das peladas pelo Mansões Paraíso, logo percebemos que não existem territórios das peladas nas principais vias do setor, salvo um lote baldio na porção sudoeste do setor - divisa com o Parque Floresta. Entendemos que tal fato se deve ao local habitual da pelada no setor, a rua. Há uma incompatibilidade entre a rua agitada pelo ir e vir intenso dos veículos e pessoas, a supervalorização dos terrenos e a pelada. O veículo e a pelada não podem existir ao mesmo tempo no mesmo espaço. O fluxo intenso, resultado da urbanização, provoca a elevação dos valores dos terrenos às margens de ruas movimentadas. Os antigos proprietários vendem tais terrenos, propícios 
à construção de prédios comerciais. Nesses termos, ao que parece, as peladas fogem do fervor intenso da urbanidade. Isso pode ser verificado na disposição territorial das peladas no Setor Mansões Paraíso.

Nas observações e entrevistas, buscamos compreender se existem elementos que conectam as peladas do Setor Mansões Paraíso e o futebol global. E, na medida que eles existem, tentamos elucidá-los. Nesse sentido, identificamos elementos importantes para a pesquisa.

O futebol global constrói signos, os quais rapidamente podem ser vistos permeando a trama das peladas. De maneira que se torna inegável que o futebol global interfere na pelada. Entretanto, em função das peladas realizarem-se por sobre as especificidades no local, essas rugosidades imprimem nas peladas um caráter de resistência aos elementos globais. As paisagens dos territórios das peladas são marcadas por elementos característicos do local e do global. Assim, tais paisagens passam a ser recortadas pelas camisas dos grandes clubes, pelas chuteiras coloridas, pelas bolas oficiais, pelas comemorações do gol parecidas com a dos craques em alta, pelos dribles e estilo de jogar dos ídolos...

No campo do visível há certa similitude entre a pelada e o futebol global. Isso surge desse campo conflitivo estabelecido no local com os vetores globais. No entanto, tais similaridades soam como um mimetismo irônico, pois essas duas formas de territorialização do futebol possuem naturezas motivacionais para suas práticas totalmente distintas. A força motriz para realização da pelada é o prazer do momento lúdico proporcionado pelo futebol, ao passo que o futebol global é mais movido pelos altos salários, pela veneração das torcidas, pela indústria do espetáculo, do que pelo deleite lúdico da prática do futebol.

\section{TERRITORIALIDADE E TEMPORALIDADE DAS PELADAS}

No Brasil, o futebol não está circunscrito aos territórios onde se dá efetivamente sua prática - nos estádios, nas chácaras de aluguel, nos lotes baldios ou mesmo na rua. Ele extrapola tais limites territoriais, chegando aos lugares mais longínquos via jogos e programas esportivos transmitidos pela televisão e pelo rádio; crônicas nas páginas de jornais e revistas; músicas, filmes e novelas; camisas de times desfilando pelas ruas; jocosidade dos colegas de trabalho quando seu time perde; nas conversas de botequim entre outros. Como salienta Castro (1962, p. 115), “o campo se 
distende para as casas, os botequins e as farmácias, depois do encontro. E, assim, até que tudo recomece em outro embate".

O futebol profissional carrega consigo uma rigidez no que se refere aos elementos para sua prática, dentre eles o espaço e o tempo. Do ponto de vista territorial, para a realização de uma partida profissional é necessário um campo com medidas oficiais. Quanto ao tempo, tais jogos devem ter horários fixos para início das partidas, além de tempos devidamente cronometrados de início e término de cada etapa ( $1^{\circ}$ tempo, $2^{\circ}$ tempo), além do tempo de intervalo.

As peladas, como expressão do local, se moldam com os processos de mutação presentes na realidade socioespacial, portanto não são fixas. Verificamos que no Setor Mansões Paraíso, as peladas não apresentam hora marcada para começar. Elas acontecem desde o amanhecer até o cair da noite. Entretanto, o horário mais recorrente da realização das peladas é ao entardecer, geralmente a partir das 17 horas. Não existe um calendário inflexível, com datas para o acontecer das peladas, a realização das mesmas está vinculada a acordos tácitos estabelecidos no cotidiano futebolístico da pelada. Portanto, podem ser vistos peladeiros jogando tanto em dias úteis, finais de semana, feriados e dias santos.

O tempo de cada jogo da pelada também é elástico, vai depender de alguns elementos. Entretanto, na maioria das peladas joga-se no sistema dois ou dez, ou seja, o jogo acaba quando uma equipe faz dois gols ou quando a partida atingir dez minutos. Em outras peladas e em alguns dias e momentos, esse tempo pode depender do número de peladeiros em cada equipe e de quantos ficarão a espera das partidas seguintes. Se houver um número grande de peladeiros esperando do lado de fora do campo para jogar, pode-se reduzir o tempo no intuito de que todos possam jogar. Em outra hipótese, se não houver nenhum peladeiro de próximo, a duração do jogo pode se dar em relação ao número de gols. Por exemplo, o time que fizer cinco gols primeiro vence. O mesmo acordo pode ser estabelecido quando nenhum dos peladeiros possui algo para marcar o tempo.

As marcas, materiais e simbólicas, construídas pelos peladeiros em sua prática, ou seja, suas territorialidades, encarnam-se no espaço atribuindo-lhes nova função. O espaço nesse momento ganha status de território. Entretanto, essa nova função atribuída com a pelada, é pouco duradoura. Ao se analisar o caso da rua, a pelada ocupa duas ou três horas no dia daquela, antes e depois disso a mesma continua tendo no trânsito de veículos 
sua principal função. Nesse caso, o território tem uma existência passageira, efêmera, pois são construídos, destruídos e reconstruídos obedecendo a uma temporalidade fugaz. Quanto ao lote baldio, os peladeiros ocupamno por um determinado horizonte temporal e depois se vão. No caso do Setor Mansões Paraíso, após o encerramento das peladas nos lotes baldios, aquelas deixam significativas marcas na paisagem destes. Os golzinhos são afixados, ficando no local mesmo ao final da pelada, além da terra batida e sem vegetação em função do ir e vir dos peladeiros. Ao contrário, na rua a paisagem após a pelada volta a ser praticamente a mesma, pois os atores ao fim da pelada geralmente retiram os golzinhos.

No que tange ao espaço, as peladas do Mansões Paraíso ocorrem, como já foi dito anteriormente, em espaços públicos e particulares. Nos espaços públicos têm-se os terrões, os lotes baldios e as ruas, já o particular conta com quadra de esportes, uma chácara com dois campos. Dentre todos esses a rua e o terreno baldio são os espaços onde é realizada a maioria das peladas. Da mesma forma que as temporalidades, as territorialidades das peladas são maleáveis.

Diante disso, entende-se que a pelada nem sempre é algo que apresenta espaços e temporalidades bem definidos. Portanto, do ponto de vista espaço-temporal elas são inconstantes/irregulares. Os espaços para a realização de uma pelada podem ser os mais diversos. Podemos encontrar peladeiros jogando nos quintais, jardins, garagens, calçadas, ruas, lotes baldios, praças públicas e em muitos outros locais. Do ponto de vista temporal, elas podem acontecer em qualquer horário do dia - manhã, tarde e noite -, com sol ou chuva. Tanto em dias úteis quanto nos feriados e finais de semana. Nesse sentido, as peladas são marcadas pela flexibilidade espaço-temporal.

\section{O PRINCÍPIO DE ORGANIZAÇÃO DO TERRITÓRIO DAS PELADAS}

Concebemos aqui o território como relações sociais projetadas no espaço. A partir das quais os indivíduos ou grupos sociais apropriam-se de determinadas frações do espaço e tais apropriações podem advir dentre outras de uma dimensão afetiva (CORREA, 1994; SOUZA, 2005). Na mesma linha entende-se territorialidade como uma coleção de práticas tanto materiais quanto simbólicas as quais permitem 
aos atores sociais se apropriarem e/ou se manterem em um território (CARA, 1994; CORRÊA, 1994; LAMECO, 1996).

As territorialidades edificam e instituem o território, que internamente para a distribuição territorial dos objetos e práticas geográficas necessitam de uma lógica organizacional. Trazendo essa discussão para o território das peladas podemos dizer que eles também carecem de um princípio organizativo para sua existência. Como salientado anteriormente para outras instâncias das peladas, também do prisma de sua organicidade, elas tendem a uma elasticidade.

Diferentemente do futebol profissional que se apresenta carregado de normas rígidas, a pelada é diferente. Com relação a isso, a pelada possui vários exemplos, sendo um deles a ausência de um juiz. Nesse caso quem marca as faltas, as saídas pelas laterais, diz se foi gol ou não? Todos os peladeiros. Há um acordo tácito de que pediu falta é falta, gritou que a bola saiu pela lateral ou linha de fundo é lateral ou escanteio. Os peladeiros que ficarem de fora do jogo, enquanto esperam para entrar são responsáveis por buscar as bolas que saem do campo, isso até como uma forma de agilizar a partida para entrar mais rápido.

Como a organização das peladas acontece no imediato e com o improviso, elementos essenciais para o futebol como as traves, a bola e o uniforme na pelada seguem essa característica. A bola pode ser de marcas oficiais, do camelô, dente de leite ou até mesmo algo que seja quase redondo - exemplo: uma laranja, bola feita de meia ou de leite mangaba. As traves também podem ser improvisadas com pedaços de tijolo, sapatos, pedras, feitas com pedaços de caixas de madeira ou armação de metal. Já quanto ao uniforme geralmente se adota um time de camisa e o outro sem.

Algo a ser salientado também, é quanto ao número de jogadores para a existência de uma pelada. A pelada pode ocorrer com um mínimo de dois jogadores, cada jogador constitui só sua equipe. Nesse caso, utiliza-se um pequeno espaço para o campo. Por outro lado, uma pelada pode acontecer com dez, quinze ou vinte peladeiros, dependendo da presença deste número de peladeiros, assim como do espaço que se tem para o jogo.

Os territórios construídos pelos peladeiros contêm, como qualquer outro território, uma série de elementos que os atribui certa organicidade. Tais territórios, ao contrário dos territórios do futebol profissional, não apresentam regras rígidas. Nesse sentido, a pelada furta $o$ futebol profissional, posto que para o peladeiro as regras figuram num 
segundo plano. O conjunto de regras que normatizam os territórios das peladas pode ser instituído tacitamente ou estabelecido à beira do campo antes, ou até mesmo durante o jogo. Por exemplo, a duração do jogo, o tamanho do campo, o número de jogadores, a "modalidade" da pelada etc., são flexíveis. Tudo isso dependerá além do espaço para a prática, também do número de peladeiros entre outros elementos.

Ao se tentar uma aproximação comparativa entre o futebol profissional e o futebol das peladas, percebemos que o primeiro, para realizar-se, necessita de uma gama de elementos, ao passo que o segundo se distingue pelo improviso. O improviso além de ser um elemento constitutivo, está no cerne da pelada.

Ao contrário do futebol profissional, as peladas independem de uma série de pré-requisitos (gramados, árbitros, regulamento, bolas oficiais, 22 jogadores, jogo de camisas...). As exigências para uma pelada são bem menores. Numa pelada tudo pode ser, e comumente é arranjado na hora, desde os jogadores, passando pelo campo e as traves, chuteiras, jogos de camisa, até a bola. Não se tem um padrão para o campo, o gol, a bola, o número de jogadores, e nem mesmo regras rígidas a serem seguidas por todas as peladas. Geralmente, tudo ocorre de acordo com o que se consegue organizar de imediato. Ao que parece a essência da pelada está no improviso.

E daí não sofrer o controle do futebol profissional e, por conseqüência, estar livre para construir sentidos lúdicos e desenvolver processos de socialização afetivos e de pertencimento de classe. Em torno disso, podemos dizer que na periferia proletária, as classes sociais empobrecidas criam, pelas peladas, campos de relações, de trocas, de enturmações, criando territórios solidários que lhes põem a suportarem o peso do mundo e, mesmo em sua penúria, ativar a alegria do gol - e da vida.

\section{CONSIDERAÇÕES FINAIS}

No percurso da pesquisa que deu origem ao presente trabalho, buscamos por meio de uma sustentação teórica e um olhar questionador, compreender e refletir sobre o fenômeno das peladas no Setor Mansões Paraíso em Aparecida de Goiânia. Como jogadores das letras, das idéias e do território geográfico, entendemos que, com o findar da pesquisa o assunto não se esgota, pois existe uma gama de elementos no mundo da pelada e do peladeiro a serem desvelados. 
No jogo rápido do nosso trabalho, a tentativa foi de dar um pontapé inicial para uma reflexão geográfica sobre os territórios informais do futebol e contribuir para a discussão do futebol no campo da Geografia. Para finalizar, diríamos que a Geografia existe enquanto ação dos geógrafos. Portanto, estes deveriam ampliar seu horizonte de atuação e interesse para além dos temas tradicionais e se debruçar também em torno de inúmeras outras questões que cercam a sociedade e o mundo contemporâneo e, evidentemente, dentre elas o futebol. Futebol esse que reúne multidões, mobiliza capitais, participa da geopolítica atual, fotografa as contradições viscerais do sujeito contemporâneo, expressa a violência, a corporeidade, as condições psíquicas e desenvolve afetos, dissidências, junções, alegrias e tristezas.

The ball game: a social spatial analysis of "peladeiro" territories

\section{ABSTRACT}

The aim of this research work is to analise territoriality among "peladeiros" (nonprofessional football players) in the Mansões Paraíso neighborhood in the city of Aparecida de Goiânia-GO, Brazil. A few methodological procedures were followed and divided in two parts: "office work" and field work. The "pelada" (the match) breaks the formality of professional football since rules, playing fields, and timetables are of a lesser importance. To the "peladeiros", the most important thing is the moment of socialization brought in by the pelada match. In the fast-paced game of this research work, we have attempted to kick off a geographical reflection on the informal territories of football.

KEYWORDS: professional football players - peladeiro - football - territories - socialization.

\section{El juego de pelota: una análisis socioespacial de los territorios de los jugadores de picaditos}

\section{RESUMEN}

El objetivo de este trabajo ha sido el de analizar las territorialidades de los jugadores de picaditos del sector Mansões Paraíso en Aparecida de Goiania-GO. Para realizarlo fueron utilizados algunos procedimientos metodológicos, los cuales constan de dos etapas, el trabajo de "gabinete" y el trabajo de campo. El picadito hurta la institucionalidad del fútbol profesional, puesto que para el jugador de picaditos, las reglas, los locales y los horarios figuran en un segundo plano. Para el jugador de picadito lo importante es el momento de sociabilidad proporcionado por el picadito. En el juego rápido de nuestro trabajo, la tentativa fue dar el puntapié inicial para una reflexión geográfica sobre los territorios informales del fútbol. 
PALABRAS-CLAVE: jugador profesional - jugadores de picaditos - fútbol - territorios - sociabilidad.

\section{NOTAS}

1 O termo terrão é inferido aos espaços destinados à prática de futebol, os quais não possuem grama, aqueles em que a pelada ocorre no solo desnudo.

2 A figura feminina aparece no futebol, até hoje, sempre em números bastante reduzidos.

\section{REFERÊNCIAS}

ALENCAR, E. Flamengo: força e alegria do povo. Rio de Janeiro: Conquista, 1970.

CARA, R. B. Territorialidade e identidade regional no Sul da Província de Buenos Aires. In: SANTOS, M.; SOUZA, M. A. A. de; SILVEIRA, M. L. (Orgs.). Território globalização e fragmentação. São Paulo: Hucitec, 1994. p. 261-269.

CASTRO, S. O futebol brasileiro: bicampeão do mundo. Rio de Janeiro: Anuário da Literatura Brasileira, 1962.

CORREAA, R. L. Territorialidade e corporação: um exemplo. In: SANTOS, M.; SOUZA, M. A. A. de; SILVEIRA, M. L. (Orgs.). Território globalização e fragmentação. São Paulo: Hucitec, 1994. p. 251-256.

SEPLAN. Secretaria de Planejamento e Desenvolvimento (Estado de Goiás). Anuário estatístico do Estado de Goiás. Goiânia: Seplan, 2003.

FÁVERO, P. M. A Geopolítica do Futebol. In: CONGRESSO BRASILEIRO DOS GEÓGRAFOS, 6. Goiânia, 2004.

HOUAISS, A.; VILLAR, M. de S. Dicionário Houaiss de língua portuguesa. Rio de Janeiro: Objetiva, 2001.

LAMECO, M. A territorialidade da Igreja Católica no estado de Minas Gerais. Espaço e Cultura, Rio de Janeiro: UERJ/NEPEC, n. 17-18, p. 119-127, dez. 1996. 
MACHADO, I. J. de R. Futebol, clãs e nação. Disponível em: < http:// Www.scielo.br/scielo.php>. Acesso em: 25 abr. 2005.

MASCARENHAS, G. Construindo a "pátria de chuteiras": elementos para uma geografia da difusão do futebol no Brasil. In: ENCONTRO ESTADUAL DE GEOGRAFIA,18. Sant'Ana do Livramento/Brasil - Rivera/Uruguai, 11 a 14 de maio de 1998, p. 93-103.

SANTOS, M. A força do lugar. In: . A natureza do espaço: técnica e tempo, razão e emoção. 2. ed. São Paulo: Hucitec, 1997. p. 249-273.

SILVA, C. A. F. da; VOTRE, S. J. Futebol, imaginário e mídia: as metáforas da discriminação no futebol brasileiro. Disponível em: $<$ http:// www.geocities.com/aotil/futebol.html>. Acesso em: 25 abr. 2005.

SOUZA, M. J. L. de. O território: sobre espaço e poder, autonomia e desenvolvimento. In: CASTRO, I. E. de; CORREA, R. L.; GOMES, P. C. da C. (Orgs.). Geografia: conceitos e temas. 7. ed. Rio de Janeiro: Bertrand Brasil, 2005. p. 77-116.

Recebido: 29 de setembro de 2006 Aprovado: 9 de novembro de 2006

Endereços para correspondência: Alexsander Batista e Silva Rua J-16 Qd. 14 Lt. 36, Papillon Park Aparecida de Goiânia-Goiás CEP 74950-030

E-mail: lexgeo@pop.com.br

Eguimar Felício Chaveiro Av. Rio Branco, Apto. 601 Bl. 09, Res. Dom Felipe Urias Margalhães

Goiânia-Goiás CEP 74565-070

E-mail: eguimar@hotmail.com 